\title{
Efeito da temperatura e de tratamentos pré-germinativos na germinação de sementes de Adenanthera pavonina $\mathrm{L}$.
}

\section{Effect of temperature and pre-germinative treatments in the germination of Adenanthera pavonina L. seeds}

\author{
Advanio Inácio Siqueira Silva ${ }^{*}$; Viviana Borges Corte²; Márcio Dias Pereira ${ }^{3}$; \\ Geraldo Rogério Faustini Cuzzuol ${ }^{4}$; Idalina Tereza de Almeida Leite ${ }^{4}$
}

\begin{abstract}
Resumo
Adenanthera pavonina L. é uma espécie arbórea nativa da Índia e de ampla distribuição em todos os estados brasileiros, cujas sementes possuem dormência e apresentam interesse medicinal e econômico. O objetivo desta pesquisa foi avaliar o efeito de diferentes temperaturas e tratamentos pré-germinativos sobre o comportamento germinativo das sementes de A. pavonina, recém colhidas. As sementes foram submetidas a três temperaturas fixas: 20,25 e $30^{\circ} \mathrm{C}$; e a cinco tratamentos pré-germinativos: desponte com alicate, atrito em lixa, imersão em ácido sulfúrico por 20 minutos, imersão em água a $80^{\circ} \mathrm{C}$ por 5 minutos e testemunha (sem tratamento). $\mathrm{O}$ vigor das sementes foi avaliado pela porcentagem, primeira contagem, velocidade e tempo médio de germinação. Utilizou-se o delineamento inteiramente casualizado, com quatro repetições e as médias foram comparadas pelo teste de Tukey, a $5 \%$ de probabilidade. $\mathrm{O}$ melhor desempenho germinativo das sementes foi nas temperaturas de 20 e $25^{\circ} \mathrm{C}$ e nos tratamentos pré-germinativos de escarificação mecânica através do desponte com alicate e atrito em lixa, e escarificação química com imersão em ácido sulfúrico por 20 minutos.
\end{abstract}

Palavras-chave: Vigor, dormência, escarificação

\begin{abstract}
Adenanthera pavonina $\mathrm{L}$. is a native tree specie from India and with extensive distribution in all Brazilian states, whose seeds have dormancy and present medicinal and economical interest. The objective of this research was to evaluate the effect of different temperatures and pre-germinative treatments on the germinative behavior of newly collected $A$. pavonina seeds. The seeds were submitted to three settled temperatures: 20,25 and $30^{\circ} \mathrm{C}$; and to five pre-germinative treatments: coating cutting with pliers, friction in sandpaper, immersion for 20 minutes in sulfuric acid, immersion in water at $80^{\circ} \mathrm{C}$ for 5 minutes and control (without any treatment). The vigor of the seeds was evaluated by the percentage, first count, speed and mean time of germination. The experimental design used was a completely randomized with four replications and the averages were compared by the Tukey test, at $5 \%$ probability. The best germinative performance of the seeds was at temperatures of 20 and $25^{\circ} \mathrm{C}$ and in the pregerminative treatments of mechanical scarification through the coating cutting with pliers and friction in sandpaper, and chemical scarification with immersion for 20 minutes in sulfuric acid.
\end{abstract}

Key words: Vigor, dormancy, scarification

\footnotetext{
Biólogo, Mestre em Botânica da Universidade Federal de Viçosa - UFV, Viçosa - MG. Cep: 36570-000. E-mail: vaninacio@ yahoo.com.br.

2 Bióloga, Doutora em Ciência Florestal da UFV, Viçosa - MG.

3 Engenheiro Agrônomo, Doutorando em Fitotecnia da UFV, Viçosa - MG.

4 Biólogos, Dr., Professores do Departamento de Ciências Biológicas da Universidade Federal do Espírito Santo - UFES, Vitória - ES.

* Autor para correspondência
} 


\section{Introdução}

Adenanthera pavonina L. (carolina, olho-depavão ou falso-sândalo), pertencente à família Leguminosae-Mimosoideae é uma espécie arbórea semidecídua, tipicamente tropical, de rápido crescimento e que produz anualmente grande quantidade de semente (LORENZI et al., 2003). Nativa da Índia e Malásia, a espécie tem sido introduzida na América (ROCAS, 2003), obtendo no Brasil boa adaptação e ampla distribuição em todos os estados brasileiros (CORRÊA, 1978).

Sua árvore apresenta potencial madeireiro e ornamental e suas sementes têm sido amplamente empregadas no artesanato (LORENZI et al., 2003), e para fins medicinais, devido a seus efeitos antiinflamatórios e analgésicos (OLAJIDE et al., 2004), além de conterem proteínas antimicrobiais (SANTOS et al., 2004).

O estudo das condições ideais para a germinação de sementes de uma dada espécie é de grande importância, principalmente pelas diferentes respostas que cada espécie pode apresentar em função da viabilidade, dormência e condições ambientais (BEWLEY; BLACK, 1994; CARVALHO; NAKAGAWA, 2000).

Entre os fatores que interferem diretamente no processo germinativo das sementes, a temperatura afeta tanto a porcentagem como a velocidade em que a germinação ocorre, pois atua diretamente na absorção de água pela semente e nas reações bioquímicas que regulam o metabolismo envolvido neste processo (MARCOS FILHO, 2005; MAYER; POLJAKOFF-MAYBER, 1989). Não existe uma temperatura ideal para o processo de germinação, sendo que a maioria das espécies tropicais germinam na faixa de temperatura que varia de 20 a $30^{\circ} \mathrm{C}$ (BORGES; RENA, 1993), uma vez que tal amplitude de temperatura é encontrada nestas regiões durante a época ideal para a germinação natural das espécies (ANDRADE et al., 2000).

Muitas espécies florestais produzem sementes que, embora sendo viáveis e tendo condições ambientais favoráveis à sua germinação, não germinam. Estas sementes são denominadas dormentes, e essa dormência pode ser de dois tipos: endógena ou exógena física. Sendo este último, o caso da A. pavonina (CARDOSO, 2004). Este autor relata que a dormência exógena física é causada pela estrutura do tegumento e/ou do pericarpo, que confere resistência e impermeabilidade dos envoltórios à absorção de água e/ou de gases, o que é muito comum em espécies da família Leguminosae (VILLIERS, 1972). O fenômeno de dormência permite que a natureza distribua a germinação no tempo (FOWLER; BIANCHETTI, 2000; FOWLER; MARTINS, 2001).

A busca de metodologias para análise de sementes florestais desempenha papel fundamental dentro da pesquisa científica e em áreas afins, onde o conhecimento dos principais processos envolvidos na germinação de sementes de espécies nativas é de vital importância para a preservação e multiplicação das espécies ameaçadas, assim como das demais espécies em programas de reflorestamento (SMIDERLE; SOUSA, 2003). Em laboratórios, diversos métodos têm sido empregados para a superação da dormência física em sementes, entre os quais podemos destacar a escarificação mecânica, química e térmica. Contudo, a aplicação e eficiência desses métodos dependem da causa e do grau da dormência, o que é bastante variável entre as espécies (LIMA; GARCIA, 1996).

A escarificação química em ácido sulfúrico é recomendada para a superação de dormência em sementes de Adenanthera pavonina L. (ZPEVAK; PAGOTTO; PEREZ, 1995; KISSMANN et al., 2008), Leucaena diversifolia Schlecht. (BERTALOT; NAKAGAWA, 1998), Bauhinia monandra Britt. (ALVES et al., 2000), Peltophorum dubium Spreng. (PIROLI et al., 2005) e Caesalpinia leiostachya Benth. (BIRUEL; AGUIAR; PAULA, 2007); a escarificação mecânica para sementes de Senna macranthera (Colladon) Irwin \& Barneby (SANTARÉM; ÁQUILA, 1995), Adenanthera pavonina L. (ZPEVAK; PAGOTTO; 
PEREZ, 1995), Leucaena diversifolia Schlecht. (BERTALOT; NAKAGAWA, 1998), Bauhinia ungulata L. (ALVES et al., 2000), Sterculia foetida L. (SANTOS; MORAIS; MATOS, 2004) e Peltophorum dubium (Spreng.) Taub. (PIROLI et al., 2005); e a escarificação térmica em água quente para sementes de Leucaena leucocephala (Lam.) de Wit (OLVERA; WEST, 1985) e Acacia mangium Willd. (LIMA; GARCIA, 1996).

Devido à importância da espécie e a necessidade de se promover, acelerar e uniformizar o processo de germinação e produção de mudas, este trabalho teve como objetivo avaliar o efeito de diferentes temperaturas e tratamentos pré-germinativos na germinação de sementes de Adenanthera pavonina.

\section{Material e métodos}

O estudo foi realizado no Laboratório de Ecofisiologia de Sementes Florestais (LESF), Departamento de Ciências Biológicas, Setor de Botânica da Universidade Federal do Espírito Santo (UFES). Sementes de A. pavonina foram coletadas, em agosto de 2005, de três matrizes situadas no campus Goiabeiras/UFES, município de VitóriaES. Após a coleta, as sementes foram beneficiadas selecionando-se as sementes intactas. Em seguida, calculou-se o teor de pureza da amostra, o número de sementes por quilo, o peso de mil sementes e o teor de água em base úmida do lote (BRASIL, 1992).

Para a superação da dormência tegumentar utilizou-se os seguintes tratamentos prégerminativos: desponte com alicate no lado oposto ao hilo, atrito em lixa de madeira $\left(n^{\circ} 36\right)$ no lado oposto ao hilo, imersão em ácido sulfúrico concentrado por 20 minutos, imersão em água a temperatura de $80^{\circ} \mathrm{C}$ por 5 minutos e testemunha (sem tratamento).

Ensaios para estudos do efeito da temperatura e dos tratamentos pré-germinativos na germinação das sementes foram realizados nas seguintes isotermas: 20,25 e $30^{\circ} \mathrm{C}$, sob luz contínua, em incubadoras do tipo B.O.D., com sementes distribuídas em placas de Petri, sobre duas folhas de papel germitest, saturado com água destilada. A germinação foi avaliada, diariamente, até o décimo quinto dia após a semeadura, sendo consideradas germinadas as sementes que apresentaram protusão de raiz primária superior a $2 \mathrm{~mm}$. O vigor das sementes foi avaliado pela germinação - porcentagem de germinação das sementes até o $15^{\circ}$ dia após a semeadura; pela primeira contagem de germinação - $\left(7^{\circ}\right.$ dia após a semeadura); pelo índice de velocidade de germinação, segundo definido por Maguire (1962) e pelo tempo médio de germinação, conforme fórmula proposta por Labouriau e Valadares (1976).

O delineamento experimental utilizado foi o inteiramente casualizado, com análise de variância (F 5\% de probabilidade) efetuada em arranjo fatorial $3 \times 5$ (temperaturas x tratamentos pré-germinativos), com quatro repetições de 25 sementes cada. As médias foram comparadas entre si pelo teste de Tukey a $5 \%$ de probabilidade utilizando-se o software SAS. Os dados de germinação e primeira contagem de germinação foram transformados em Arc seno $((x+a) / 10)^{1 / 2}$, já que não atenderam ao padrão de normalidade exigido para a análise de variância.

\section{Resultados e Discussão}

A análise de variância apontou interação significativa $(p<0,05)$ entre tratamento prégerminativo e temperatura em todos os parâmetros avaliados.

As sementes de A. pavonina apresentaram teor de umidade baixo $(8,99 \%)$, e a espécie pode ser classificada como ortodoxa (Tabela 1), o que por definição as caracteriza como sementes dispersas com teor de umidade bastante reduzido, garantindo uma viabilidade embrionária mais prolongada (LANG, 1965), o que varia com a espécie. O peso de mil sementes foi de 304 gramas resultando no total de 3.290 sementes por quilo. Observa-se ainda nesta tabela que o grau de pureza foi alto para as sementes avaliadas. 
Tabela 1. Características físicas das sementes de Adenanthera pavonina L. obtidas imediatamente após a coleta (campus Goiabeiras - UFES, Vitória-ES).

\begin{tabular}{cccc}
\hline Teor de água \% & Pureza \% & Peso de 1000 sementes $(\mathrm{g})$ & $\begin{array}{c}\text { Número de sementes por quilo } \\
\text { (Sementes } / \mathrm{Kg})\end{array}$ \\
\hline 8,99 & 95,41 & 304,00 & 3.290 \\
\hline
\end{tabular}

A maior porcentagem de germinação das sementes de A. pavonina foi obtida quando se utilizou as temperaturas de 20 e $25^{\circ} \mathrm{C}$ combinadas com os tratamentos pré-germinativos de desponte com alicate, atrito em lixa e imersão em ácido sulfúrico. A $30^{\circ} \mathrm{C}$ o melhor desempenho germinativo foi para os tratamentos de lixa e ácido sulfúrico, os quais não diferiram estatisticamente. Estes tratamentos não apresentaram diferença estatística, entre si , em todas as temperaturas testadas, corroborando com os resultados obtidos por Zpevak, Pagotto e Perez (1995), que os indicaram como os mais adequados para promover a germinação das sementes de $A$. pavonina à temperatura de $25^{\circ} \mathrm{C}$ (Tabela 2 ).

A testemunha apresentou porcentagem de germinação nula, em todas as temperaturas testadas (Tabela 2). Este resultado confirma a presença de dormência física nas sementes de A. pavonina, provavelmente devido à estrutura impermeável do tegumento. Nesse caso, os envoltórios funcionam como uma barreira à germinação, os quais o embrião não consegue superar. Segundo Bewley e Black (1994), a dormência imposta pelos envoltórios tem os seguintes efeitos sobre o embrião: interferência na absorção de água, no alongamento embrionário, nas trocas gasosas e impedimento à saída de inibidores e/ou fonte de inibidores na germinação.

O uso de água quente é um tratamento muito mais prático do que a lixa ou punção dos envoltórios com alicate. Entretanto, para sementes de A. pavonina o tratamento de imersão em água a $80^{\circ} \mathrm{C}$, por 5 minutos, não resultou em incremento de germinação em relação à testemunha, mostrando-se ineficiente para a superação da dormência tegumentar das sementes, desta espécie (Tabela 2). O tempo de exposição das sementes à água quente pode ter sido decisivo nesse resultado, pois este tempo pode ter sido insuficiente para promover a quebra de dormência ou suficiente para provocar a morte das sementes, como registrado para diversas espécies como Senna macranthera (Colladon.) Irwin \& Barneby (SANTARÉM; ÁQUILA, 1995), Bauhinia monandra Britt. e B. ungulata L. (ALVES et al., 2000), Mimosa caesalpinaiaefolia Benth. (BRUNO et al., 2001), Bauhinia divaricata L. (ALVES et al., 2004) e Peltophorum dubium (Spreng.) Taub. (OLIVEIRA; DAVIDE; CARVALHO, 2003; PIROLI et al., 2005). Entretanto, em sementes de Schizolobium parayba (Vellozo) Blake, imersas em água fervente por intervalos de 4 a 10 minutos, Bianchetti e Ramos (1981) obtiveram percentuais de germinação acima de $84 \%$, o que mostra o quanto a resposta das espécies com dureza tegumentar aos tratamentos pré-germinativos são variáveis.

A escarificação mecânica e química, promovendo fissuras no envoltório das sementes, foi um método bastante eficaz na superação da dormência tegumentar deste estudo, corroborando os resultados anteriormente obtidos com escarificação mecânica e química por Zpevak; Pagotto e Perez (1995) e escarificação química por Kissmann et al. (2008), para $A$. pavonina. A escarificação mecânica por lixa mostrou-se eficiente também na superação da dormência em sementes de Bauhinia ungulata L. (ALVES et al., 2000), Hymenaea courbaril L., Schizolobium parahyba (Vell.) Blake., Enterolobium contortisiliquum (Vell.) Morong. (AZEREDO et al., 2003), Sterculia foetida L. (SANTOS; MORAIS; MATOS, 2004) e Peltophorum dubium (Spreng.) Taub. (PIROLI et al., 2005). Entretanto, esse tratamento foi ineficiente em outros casos, por exemplo, ao provocar a contaminação por fungos, como ocorreu em sementes de Stryphnodendron 
polyphyllum (TAMBELINI, 1994). A escarificação química com ácido sulfúrico apresentou destaque também na superação da dormência física das sementes de Senna macranthera (Colladon.) Irwin \& Barneby (SANTARÉM; ÁQUILA, 1995), Bauhinia monandra Britt. (ALVES et al., 2000), Stylosanthes viscosa Sw. (ARAÚJO et al., 2000), Mimosa caesalpiniaefolia Benth. (BRUNO et al., 2001) e Parkia nitida Miquel. (CRUZ; CARVALHO; LEÃO, 2001).

A barreira à entrada de água nas sementes pode ser atribuída a várias partes dos envoltórios, como por exemplo, uma cutícula serosa, a suberina, o tecido paliçádico e as camadas de macroesclereídes
(PEREZ, 2004). Acredita-se que a ação do ácido sulfúrico no amolecimento do tegumento da semente possa ser resultado da remoção da cutícula e das camadas de macrosclereídes (EGLEY, 1989).

O desponte do tegumento das sementes com alicate apresentou um bom desempenho germinativo apenas a 20 e $25^{\circ} \mathrm{C}$ (Tabela 2). Este método foi eficaz na superação de dormência tegumentar em sementes de Enterolobium contortisiliquum (Vell) Morong (BORGES; BORGES; TELES, 1980), Acacia bonariensis Gill e Mimosa bimucronata (D.C.) O. Kuntze (FERREIRA; LIPP JOÃO; HEUSER, 1992), Senna macranthera (Colladon.) Irwin \& Barneby (SANTARÉM; ÁQUILA, 1995) e Bauhinia divaricata L. (ALVES et al., 2004).

Tabela 2. Germinação (\%) de sementes de Adenanthera pavonina L. submetidas a diferentes temperaturas e tratamentos pré-germinativos.

\begin{tabular}{lccc}
\hline \multicolumn{1}{c}{ Tratamento pré-germinativo } & \multicolumn{3}{c}{ Temperatura $\left({ }^{\circ} \mathrm{C}\right)$} \\
\cline { 2 - 4 } & 20 & 25 & 30 \\
\hline Desponte com alicate & $88 \mathrm{Aa}$ & $77 \mathrm{Aa}$ & $42 \mathrm{Bb}$ \\
Atrito em lixa & $88 \mathrm{Aa}$ & $87 \mathrm{Aa}$ & $67 \mathrm{Aa}$ \\
Imersão em $\mathrm{H}_{2} \mathrm{SO}_{4}$ por 20 minutos & $91 \mathrm{Aa}$ & $71 \mathrm{Aa}$ & $65 \mathrm{Aa}$ \\
Imersão em $\mathrm{H}_{2} \mathrm{O}$ a $80^{\circ} \mathrm{C}$ por 5 minutos & $0 \mathrm{Ba}$ & $0 \mathrm{Ba}$ & $0 \mathrm{Ca}$ \\
Testemunha (sem tratamento) & $0 \mathrm{Ba}$ & $0 \mathrm{Ba}$ & $0 \mathrm{Ca}$ \\
\hline $\mathrm{CV}(\%)$ & 9,6 & 10,11 & 8,5 \\
\hline
\end{tabular}

Médias seguidas pela mesma letra maiúscula na coluna e minúscula na linha não diferem entre si, pelo teste de Tukey a $5 \%$ de probabilidade.

A velocidade em que o processo de germinação ocorre é fundamental para a sobrevivência e o desenvolvimento da espécie, pois diminui o tempo de exposição da semente às condições adversas e às intempéries. A primeira contagem de germinação é um indicador da velocidade de germinação.

Para as sementes de A. pavonina, as temperaturas de incubação 20 e $25^{\circ} \mathrm{C}$ foram as que se mostraram mais favoráveis em acelerar o processo de germinação (Tabela 3), confirmando os resultados obtidos por Zpevak e Perez (1993), quando as sementes desta espécie foram escarificadas com ácido sulfúrico.
Entre os tratamentos pré-germinativos que se mostraram mais promissores, o desponte das sementes com alicate apresentou o mais alto vigor apenas a 20 e $25^{\circ} \mathrm{C}$, ao passo que os tratamentos com atrito em lixa e imersão em ácido sulfúrico mostraram alta eficiência em todas as temperaturas testadas. Além disso, à temperatura de $30^{\circ} \mathrm{C}$, a escarificação com lixa apresentou a maior porcentagem de germinação na primeira contagem (Tabela 3). Na escarificação mecânica, a absorção de água pelas sementes é favorecida pelas ranhuras promovidas no tegumento da semente, o que aumenta a sua permeabilidade e facilita a embebição 
e a aceleração do início do processo de germinação (FRANKE; BASEGGIO, 1998). Cabe ressaltar que a escarificação mecânica utilizada, para promover estas ranhuras, deve ser cuidadosa a ponto de não provocar injúrias ao embrião.

Em todas as temperaturas testadas não houve germinação na primeira contagem para os tratamentos imersão em água a $80^{\circ} \mathrm{C}$ e testemunha (Tabela 3).

Os valores médios do índice de velocidade de germinação (Tabela 4) apresentaram diferenças significativas, entre os tratamentos testemunha e imersão em água a $80^{\circ} \mathrm{C}$, para os demais tratamentos pré-germinativos, independente da temperatura de incubação utilizada. Os tratamentos desponte com alicate, atrito em lixa e imersão em ácido sulfúrico não diferiram, entre si, para todas as temperaturas testadas, exceto a $30^{\circ} \mathrm{C}$ no tratamento com alicate.
$\mathrm{O}$ índice de velocidade de germinação apontou as temperaturas de 20 e $25^{\circ} \mathrm{C}$ como as temperaturas mais promissoras para a germinação de A. pavonina, no que contraria os resultados encontrados por Souza et al. (2007), cujos experimentos indicaram as temperaturas de 30 e $35^{\circ} \mathrm{C}$. O uso de desponte com alicate apresentou alto IVG a $20^{\circ} \mathrm{C}(3,93)$ e $25^{\circ} \mathrm{C}(4,39)$, e baixo a $30^{\circ} \mathrm{C}(2,86)$. A escarificação com lixa e ácido sulfúrico apresentou alto IVG em todas as temperaturas testadas, sendo que para a temperatura de $30^{\circ} \mathrm{C}$ o tratamento de atrito em lixa diferiu estatisticamente das sementes tratadas com desponte com alicate, as quais apresentaram baixo IVG. Para a temperatura de $30^{\circ} \mathrm{C}$ no tratamento com lixa, o IVG obtido neste estudo foi semelhante ao encontrado por Souza et al. (2007), sendo que o mesmo não foi observado para a temperatura de $25^{\circ} \mathrm{C}$. (Tabela 4).

Tabela 3. Primeira contagem de germinação (\%) de sementes de Adenanthera pavonina L. submetidas a diferentes temperaturas e tratamentos pré-germinativos.

\begin{tabular}{lccc}
\hline \multirow{2}{*}{ Tratamento pré-germinativo } & \multicolumn{3}{c}{ Temperatura $\left({ }^{\circ} \mathrm{C}\right)$} \\
\cline { 2 - 3 } & \multicolumn{2}{c}{ Primeira contagem da germinação (\%) } \\
\hline Desponte com alicate & $76 \mathrm{Aa}$ & $65 \mathrm{Aa}$ & $42 \mathrm{Bb}$ \\
Atrito em lixa & $74 \mathrm{ABa}$ & $79 \mathrm{Aa}$ & $65 \mathrm{Aa}$ \\
Imersão em $\mathrm{H}_{2} \mathrm{SO}_{4}$ por 20 minutos & $62 \mathrm{Ba}$ & $66 \mathrm{Aa}$ & $55 \mathrm{ABa}$ \\
Imersão em $\mathrm{H}_{2} \mathrm{O}$ a $80^{\circ} \mathrm{C}$ por 5 minutos & $0 \mathrm{Ca}$ & $0 \mathrm{Ba}$ & $0 \mathrm{Ca}$ \\
Testemunha (sem tratamento) & $0 \mathrm{Ca}$ & $0 \mathrm{Ba}$ & $0 \mathrm{Ca}$ \\
\hline $\mathrm{CV}(\%)$ & 14,6 & 11,2 & 5,2 \\
\hline
\end{tabular}

Médias seguidas pela mesma letra maiúscula na coluna e minúscula na linha não diferem entre si, pelo teste de Tukey a $5 \%$ de probabilidade.

Tabela 4. Índice de velocidade de germinação (IVG) de sementes de Adenanthera pavonina L. submetidas a diferentes temperaturas e tratamentos pré-germinativos.

\begin{tabular}{lccc}
\hline \multicolumn{1}{c}{ Tratamento pré-germinativo } & \multicolumn{3}{c}{ Temperatura $\left({ }^{\circ} \mathrm{C}\right)$} \\
\cline { 2 - 4 } & 20 & 25 & 30 \\
\hline Desponte com alicate & $3,93 \mathrm{Aa}$ & $4,39 \mathrm{Aa}$ & $2,86 \mathrm{Bb}$ \\
Atrito em lixa & $3,73 \mathrm{Aa}$ & $4,94 \mathrm{Aa}$ & $4,07 \mathrm{Aa}$ \\
Imersão em $\mathrm{H}_{2} \mathrm{SO}_{4}$ por 20 minutos & $3,38 \mathrm{Aa}$ & $3,81 \mathrm{Aa}$ & $3,44 \mathrm{ABa}$ \\
Imersão em $\mathrm{H}_{2} \mathrm{O}$ a $80^{\circ} \mathrm{C}$ por 5 minutos & $0 \mathrm{Ba}$ & $0 \mathrm{Ba}$ & $0 \mathrm{Ca}$ \\
Testemunha (sem tratamento) & $0 \mathrm{Ba}$ & $0 \mathrm{Ba}$ & $0 \mathrm{Ca}$ \\
\hline $\mathrm{CV}(\%)$ & 12,3 & 13,5 & 5,8 \\
\hline
\end{tabular}

Médias seguidas pela mesma letra maiúscula na coluna e minúscula na linha não diferem entre si, pelo teste de Tukey a $5 \%$ de probabilidade. 
Quanto menor o tempo médio de germinação, maior a velocidade de germinação, o que constitui um bom parâmetro de avaliação do vigor de sementes. A $20^{\circ} \mathrm{C}$, as sementes quando escarificadas mecanicamente e quimicamente apresentaram o mais alto tempo médio de germinação, indicando que a temperatura mais baixa aumenta o tempo médio em que as sementes germinam, provavelmente devido à redução da velocidade das reações bioquímicas envolvidas no processo da germinação (Tabela 5).

A elevação da temperatura proporcionou uma redução no tempo médio de germinação, como observado, para as temperaturas de 25 e $30^{\circ} \mathrm{C}$ nos tratamentos alicate, lixa e ácido sulfúrico (Tabela 5). Temperaturas elevadas podem aumentar a velocidade de germinação da espécie em estudo, o que diminui o tempo gasto para a germinação e emergência da semente no campo, bem como o tempo em que a semente e plântula ficam expostas às condições adversas do ambiente.

Em todas as temperaturas testadas, o tempo médio de germinação para os tratamentos de imersão em água e testemunha foi nulo (0), visto que não houve germinação das sementes, não sendo possível estimar o tempo médio de germinação para as sementes submetidas a estes tratamentos (Tabela 5).

Tabela 5. Tempo médio de germinação (em dias) de sementes de Adenanthera pavonina L. submetidas a diferentes temperaturas e tratamentos pré-germinativos.

\begin{tabular}{lccc}
\hline \multirow{2}{*}{ Tratamento pré-germinativo } & \multicolumn{3}{c}{ Temperatura $\left({ }^{\circ} \mathrm{C}\right)$} \\
\cline { 2 - 4 } & 20 & 25 & 30 \\
\hline Desponte com alicate & $6,02 \mathrm{Ba}$ & $4,943 \mathrm{ABb}$ & $4,02 \mathrm{Bb}$ \\
Atrito em lixa & $6,62 \mathrm{ABa}$ & $4,77 \mathrm{ABb}$ & $4,37 \mathrm{Bb}$ \\
Imersão em $\mathrm{H}_{2} \mathrm{SO}_{4}$ por 20 minutos & $7,47 \mathrm{Aa}$ & $5,038 \mathrm{Ab}$ & $5,34 \mathrm{Ab}$ \\
Imersão em $\mathrm{H}_{2} \mathrm{O}$ a $80^{\circ} \mathrm{C}$ por 5 minutos & $0 \mathrm{Ca}$ & $0 \mathrm{Ca}$ & $0 \mathrm{Ca}$ \\
Testemunha (sem tratamento) & $0 \mathrm{Ca}$ & $0 \mathrm{Ca}$ & $0 \mathrm{Ca}$ \\
\hline $\mathrm{CV}(\%)$ & 11,8 & 15,7 & 11,2 \\
\hline
\end{tabular}

*Médias seguidas pela mesma letra maiúscula na coluna e minúscula na linha não diferem entre si, pelo teste de Tukey a $5 \%$ de probabilidade.

\section{Conclusões}

As temperaturas que proporcionaram melhor desempenho germinativo das sementes de $A$. pavonina foram às de 20 e $25^{\circ} \mathrm{C}$, e os tratamentos pré-germinativos mais eficientes na superação da dormência física das sementes testadas foram: escarificação mecânica através do desponte com alicate e atrito em lixa e escarificação química pela imersão em ácido sulfúrico, por 20 minutos.

\section{Agradecimentos}

À agência PETROBRÁS, pela bolsa concedida.

\section{Referências}

ALVES, A. U.; DORNELAS, C. S. M.; BRUNO, R. L. A.; ANDRADE, L. A.; ALVES, E. U. Superação de dormência em sementes de Bauhinia divaricata L. Acta Botanica Brasílica, São Paulo, v. 18, n. 4, p. 871-879, 2004.

ALVES, M. C. S.; MEDEIROS FILHO, S.; ANDRADE NETO, M.; TEÓFILO, E. M. Superação da dormência em sementes de Bauhinia monandra Britt. e Bauhinia ungulata L. -Caesalpinoideae. Revista Brasileira de Sementes, Brasília, v. 22, n. 2, p. 139-144, 2000.

ANDRADE, A. C. S.; SOUZA, A. F.; RAMOS, F. N.; PEREIRA, T. S.; CRUZ, A. P. M. Germinação de sementes de jenipapo: temperatura, substrato e morfologia do desenvolvimento pós-seminal. Pesquisa Agropecuária Brasileira, Brasília, v. 35, n. 3, p. 609-615, 2000. 
ARAÚJO, E. F.; ARAÚJO, R. F.; SILVA, R. F.; GOMES, J. M. Avaliação de diferentes métodos de escarificação das sementes e frutos de Stylosanthes viscosa Sw. Revista Brasileira de Sementes, Brasília, v. 22, n. 1, p. 18-22, 2000.

AZEREDO, G. A.; BRUNO, R. L. A.; ANDRADE, L. A.; CUNHA, A. O. Germinação em sementes de espécies florestais da mata atlântica (Leguminosae) sob condições de casa de vegetação. Pesquisa Agropecuária Tropical, Goiânia, v. 33, n. 1, p. 11-16, 2003.

BERTALOT, M. J.; NAKAGAWA, J. Superação da dormência em sementes de Leucaena diversifolia (Schlecht.) Bentham K 156. Revista Brasileira de Sementes, Brasília, v. 20, n. 1, p. 39-42, 1998.

BEWLEY, J. D.; BLACK, M. Seeds: physiology of development and germination. 2.ed. New York: Plenum Press, 1994.

BIANCHETTI, A.; RAMOS, A. Quebra de dormência de guapuruvu (Schizolobium parayba (Vellozo) Blake). Boletim de Pesquisa Florestal, Colombo, v. 1, n. 3, p. 69-76, 1981.

BIRUEL, R. P.; AGUiAR, I. B.; PAUlA, R. C. Germinação de sementes de pau-ferro submetidas a diferentes condições de armazenamento, escarificação química, temperatura e luz. Revista Brasileira de Sementes, Pelotas, v. 29, n. 3, p. 151-159, 2007.

BORGES, E. E. L.; BORGES, R. C. G.; TELES, F. F. F. Avaliação da maturação e dormência de sementes de orelha-de-negro. Revista Brasileira de Sementes, Brasília, v. 2, n. 2, p. 29-32, 1980.

BORGES, E. E. L.; RENA, A. B. Germinação de sementes. In: AGUIAR, I. B.; PIÑA-RODRIGUES, F. C. M.; FIGLIOLIA, M. B. (Org.). Sementes Florestais Tropicais. Brasília: ABRATES, 1993. p. 83-135.

BRASIL. Ministério da Agricultura e Reforma Agrária. Regras para análise de sementes. Brasília: SNDA/ DNDV/CLAV, 1992.

BRUNO, R. L. A.; ALVES, E. U.; OLIVEIRA, A. P.; PAULA, R. C. Tratamentos pré-germinativos para superar a dormência de sementes de Mimosa caesalpiniaefolia Benth. Revista Brasileira de Sementes, Brasília, v. 23, n. 2, p. 136-143, 2001.

CARDOSO, V. J. M. Dormência: estabelecimento do processo. In: FERREIRA, A. G.; BORGHETTI, F. (Org.). Germinação do básico ao aplicado. Porto Alegre: Artmed, 2004. p. 95-108.

CARVALHO, N. M.; NAKAGAWA, J. Sementes: ciência, tecnologia e produção. 4.ed. Jaboticabal: FUNEP, 2000.
CORRÊA, M. P. Dicionário das plantas úteis do Brasil $e$ das exóticas cultivadas. Rio de Janeiro: Imprensa Nacional, 1978. v. 2.

CRUZ, E. D.; CARVALHO, J. E. U.; LEÃO, N. V. M. Métodos para superação da dormência e biometria de frutos e sementes de Parkia nitida Miquel. (Leguminosae - Mimosoideae). Acta Amazônica, Manaus, v. 31, n. 12, p. 167-177, 2001.

EGLEY, G. H. Water-impermeable seed coverings as barriers to germination. In: TAYLORSON, R. B. (Org.). Recents advances in the development and germination of seeds. New York: Plenum, 1989. p. 207-223.

FERREIRA, A. G.; LIPP JOÃO, K. H. L.; HEUSER, E. D. Efeitos de escarificação sobre a germinação e do pH no crescimento de Acacia bonariensis Gill e Mimosa bimucronata (D.C.) O. K. Revista Brasileira de Fisiologia Vegetal, Londrina, v. 4, n. 1, p. 63-65, 1992.

FOWLER, J. A. P.; BIANCHETTI, A. Dormência em sementes florestais. Colombo: EMBRAPA Florestas, 2000. (Documentos, 40).

FOWLER, J.A. P.; MARTINS, E. G. Manejo de sementes de espécies florestais. Colombo: EMBRAPA Florestas, 2001. (Documentos, 58).

FRANKE, L. B.; BASEGGIO, J. Superação da dormência em sementes de Desmodium incanum DC. e Lathyrus nevosus Lam. Revista Brasileira de Sementes, Brasília, v. 20, n. 2, p. 182-186, 1998.

KISSMANN, C.; SCALON, S. P. Q.; SCALON FILHO, H.; RIBEIRO, N. Tratamentos para quebra de dormência, temperaturas e substratos na germinação de Adenanthera pavonina L. Ciência e Agrotecnologia, Lavras, v. 32, n. 2, p. 668-674, 2008.

LABOURIAU, L. G.; VALADARES, M. E. B. On the germination of seeds Calotripes procera (Ait.). Anais da Academia Brasileira de Ciências, Rio de Janeiro, v. 48, n. 2, p. 263-284, 1976.

LANG,A. Effects of some internal and external conditions on seed germination. Encyclopedia of Plant Physiology, Berlin, v. 15, n. 2, p. 848-893, 1965.

LIMA, D.; GARCIA, L. C. Avaliação de métodos para o teste de germinação em sementes de Acacia mangium Willd. Revista Brasileira de Sementes, Brasília, v. 18, n. 2, p. 180-185, 1996.

LORENZI, H.; SOUZA, H. M.; TORRES, M. A. V.; BACHER, L. B. Árvores exóticas no Brasil: madeireiras, ornamentais e aromáticas. Nova Odessa: Instituto Plantarum, 2003. 
MAGUIRE, J. D. Speed of germination aid in selection and evaluation for seedling emergence and vigor. Crop Science, Madison, v. 2, n. 2, p. 176-177, 1962.

MARCOS FILHO, J. Fisiologia de sementes de plantas cultivadas. FEALQ: Piracicaba, 2005.

MAYER, A. C.; POLJAKOFF-MAYBER, A. The germination of seeds. 4.ed. London: Pergamon Press, 1989.

OLAJIDE, O. A.; ECHIANU, C. A.; ADEDAPO, A. D. A.; MAKINDE J. M. Anti-inflammatory studies on Adenanthera pavonina seed extract. Inflammopharmacology, Leiden, v. 12, n. 2, p. 196-202, 2004.

OLIVEIRA, L. M.; DAVIDE, A. C.; CARVALHO, M. L. M. Avaliação de métodos para quebra da dormência e para a desinfestação de sementes de canafístula (Peltophorum dubium (Sprengel) Taubert). Revista Árvore, Viçosa, v. 27, n. 5, p. 597-603, 2003.

OLVERA, E.; WEST, S. H. Aspects of germination of leucaena. Tropical Agriculture, Trinidad, v. 62, n. 1, p. 68-72, 1985.

PEREZ, S. C. J. G. A. Envoltórios. In: FERREIRA A. G.; BORGHETTI, F. (Org.). Germinação do básico ao aplicado. Porto Alegre: Artmed, 2004. p. 125-134.

PIROLI, E. L.; CUSTÓDIO, C. C.; ROCHA, M. R. V.; UDENAL, J. L. Germinação de sementes de canafístula Peltophorum dubium (Spreng.) Taub. tratadas para superação da dormência. Colloquium Agrariae, Presidente Prudente, v. 1, n. 1, p. 13-18, 2005.

ROCAS, A. N. Adenanthera pavonina L. In: VOZZO, J. A. (Org.). Tropical tree seed manual. United States: Department of Agriculture Forest Service, 2003. p. 269271.

SANTARÉM, E. R.; AQUILA, M. E. A. Influência de métodos de superação de dormência e do armazenamento na germinação de sementes de Senna macranthera
(Colladon) Irwin \& Barneby (Leguminosae). Revista Brasileira de Sementes, Brasília, v. 17, n. 2, p. 205-209, 1995.

SANTOS, I. S.; CUNHA, M.; MACHADO, O. L. T.; GOMES, V. M. A chitinase from Adenanthera pavonina L. seeds: purification, characterisation and immunolocalisation. Plant Science, Irlanda, v. 167, n. 6, p. 1203-1210, 2004.

SANTOS, T. O.; MORAIS, T. G. O.; MATOS, V. P. Escarificação mecânica em sementes de Chichá (Stercullia foetida L.). Revista Árvore, Viçosa, v. 28, n. 1, p. 1-6, 2004.

SMIDERLE, O. J.; SOUSA, R. C. P. Seed dormancy of paricarana tree (Bowdichia virgilioides Kunth) Fabaceae - Papilionidae. Revista Brasileira de Sementes, Pelotas, v. 25, n. 2, p. 48-53, 2003.

SOUZA, E. B.; PACHECO; M. V.; MATOS, V. P.; FERREIRA, R. L. C. Germinação de sementes de Adenanthera pavonina L. em função de diferentes temperaturas e substratos. Revista Árvore, Viçosa, v. 31, n. 3, p. 437-443, 2007.

TAMBELINI, M. Tratamentos pré-germinativos e aspectos ecofisiológicos na germinação de sementes de Stryphnodendron polyphyllum Mart. 1994. Dissertação. (Mestrado em Ecologia e Recursos Naturais) Universidade Federal de São Carlos, São Carlos.

VILLIERS, T. A. Seed dormancy. In: KOZLOWSKY, T. T. (Org.). Seed biology. New York: Academic Press, 1972. v. 2, p. 220-282.

ZPEVAK, F. A.; PAGOTTO, T. C. S.; PEREZ, S. C. G. A. Quebra de dormência em sementes de Adenanthera pavonina L. Informativo ABRATES, Londrina, v. 5, n. 2, p. 202, 1995.

ZPEVAK, F. A.; PEREZ, S. C. J. G. A. Efeitos da temperatura na germinação de sementes de Adenanthera pavonina L. Informativo ABRATES, Londrina, v. 3, n. 3, p. $75,1993$. 
